\title{
Development of a concept for a holistic knowledge-based additive manufacturing over the entire lifecycle
}

\author{
Cordula Auth, Alexander Arndt, Reiner Anderl \\ TU Darmstadt, Department of Computer Integrated Design, Otto-Berndt-Str. 2, \\ 64287 Darmstadt, Germany \\ authedik.tu-darmstadt.de
}

\begin{abstract}
Based on the increasing digitalization, collecting data and using it for process optimization gets more important nowadays. In the field of additive manufacturing (AM), data are neither collected nor analyzed standardly over the entire lifecycle. Nevertheless, the optimization of the process of AM with the help of process information is one possibility to increase the quality of manufactured components. Thus, the data handling and usage in the field of AM forms a huge research gap. Therefore, the main aim of this paper is the development of a concept for a holistic knowledge-based AM over the entire lifecycle starting at material production, following by product development, production process with pre-, in- and post-processing, use phase of the product and ending with recycling or disposal.

The introduction deals with the definition of and the motivation for a knowledge-based AM. The following part explains the AM process chain and the lifecycle of a product. The next part contains the concept for the development of a knowledge-based AM. Therefore, the AM process chain needs to be connected with the lifecycle and all steps of the new created process need to be defined. Aims of the concept are the collection of process data and the efficient use and storage of the collected data. With the help of the data, an optimization of the quality and process reliability is possible. The last part of the paper covers an outlook on the implementation of the concept. The outlook and conclusion highlight potential benefits of the knowledge-based AM.
\end{abstract}

Keywords: Additive manufacturing, process chain, lifecycle, data management, process optimization

\section{Introduction}

The importance and the industrial usage of AM grew over the last years. The Wohlers Report 2017 shows an increase of the AM patent applications from 1996 to 2016, with a surprising 7.7 times grow from 2013 to 2016 [1]. Besides, the number of AM system manufacturer nearly tripled from 2013 to 2016 [2]. Furthermore, there exist some examples of the serial use of AM parts in different industries. Since 2014, Airbus integrated printed parts in the airplane A350 XWB [3,4]. Another example is a German supplier for automobile industry, who produces over 40.000 plastic parts for costumers

adfa, p. 1, 2011.

(C) Springer-Verlag Berlin Heidelberg 2011 
[5]. The examples emphasize the increasing acceptance and the benefits of AM methods.

The increasing usage of AM methods results from the improvement of the manufacturing methods and special requirements of the costumers. In some cases, the economic efficiency of AM methods exceeds the economic efficiency of conventional manufacturing methods. AM methods help to produce small lot sizes or individualized and complex geometries in an economic efficient way. The benefits of AM methods result from the short and mostly digital process chain. A complex programming do not take place compared to a milling process chain. [6]

In addition to the trend of AM, there is an increasing trend of digitalization. New use cases grow through the benefits of Industrie 4.0 and digitalization. Examples are the formation of dynamic value networks as horizontal integration or the linkage of production systems as vertical integration [7]. Through Industrie 4.0, new business models occur. A precondition for the efficient implementation of Industrie 4.0 strategies is the availability of relevant information and data in real time. Therefore, productions are equipped with sensors and incoming data are saved and used. The connection and linkage of humans, systems and objects foster the formation of value networks. These can be optimized on their costs, quality or even sustainability. [8]

The aim of the holistic knowledge-based AM is the efficient use of the benefits of digitalization and Industrie 4.0 for the optimization of the process of AM and the quality of every manufactured component. Therefore, the process chain of AM is integrated in the product lifecycle. Thus, the following part deals with the AM process chain and the product lifecycle. After this, the next section contains the concept for the holistic knowledge-based AM over the entire lifecycle. The first step is the integration of the AM process chain into the lifecycle. An explanation of the new phases follows. The main part of the concept is the collection of data for the process optimization. Therefore, it follows a description which data needs to be collected. An outlook on the implementation of this concept follows in the next part. The last part deals with an outlook and a conclusion of the paper.

\section{AM process chain and product lifecycle}

This chapter deals with a definition of the AM process chain and a definition of the product lifecycle with different views. The AM process chain stands out for a flexible, direct and rapid fabrication of parts based on 3D CAD data. Compared to conventional manufacturing methods, AM methods do not need intermediate stages as for example tool manufacturing. $[9,10]$ The AM process chain is described in different ways by various authors, but the tasks are more or less the same following any process chain [for example 10]. In the official VDI standard, the AM process chain has three process steps on the first level of abstraction: the pre-processing, the in-processing and the postprocessing [9].

During the pre-processing, the machine preparation, the creation and transformation of the data, orientation and positioning of the part, generating of support structures and 
the slicing process take place. After these steps, the in-processing starts. The in-processing means the manufacturing process of the part. The laser or nozzle build the part layer-on-layer through following the path of the sliced geometry. After finishing the building process, all actions for unloading and part removal take place in this step. The last step is the post-processing. One task of the post-processing is the removing of the powder or the support structures. Another task can be the improvement of the characteristics of the manufactured component, for example a surface treatment.

The three phases of pre-, in- and post-processing with the depending activities are shown in figure 1.

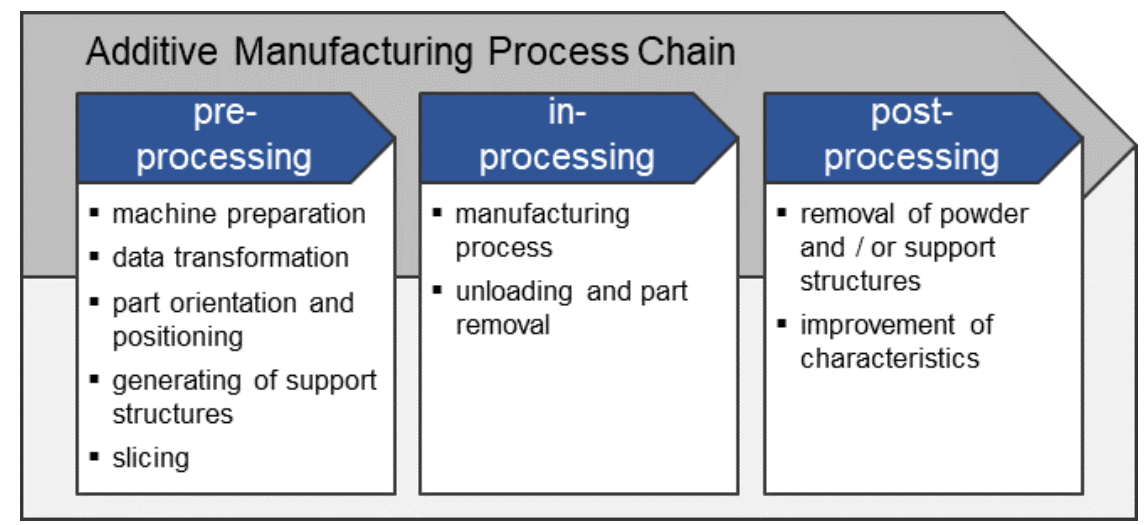

Fig. 1. The AM process chain with the three phases pre-, in- and post-processing

After explaining the AM process chain, this chapter deals with the product lifecycle. There exist different directions of the product lifecycle: an economical view, an ecological view and an information technological view [11]. The economical view deals with the relation of sales, earnings and costs. The ecological view describes the material and information flow. There exist four phases: material production, manufacturing, product use and recycling or disposal. The information technological view comprises seven phases, which are represented in a loop. The first four form the product development. These are product planning, construction, work preparation and product manufacturing. The phases product distribution, product use and product recycling or disposal follow the product development. [11, 12]

Like explained, this is the actual state of the art for the AM process chain and the lifecycle. This state of the art is not sufficient to realize a holistic knowledge-based AM. Therefore, the AM process chain needs to be integrated into the lifecycle as one fundamental step in the following chapter. 


\section{Concept for a holistic knowledge-based AM over the entire lifecycle}

After explaining the AM process chain and different views of the product lifecycle, the concept for a knowledge-based AM is generated. To develop a method for a holistic knowledge-based AM, the ecological and the information technical views of the product lifecycle are important. The first step is the connection between the AM process chain and the product lifecycle. Therefore, in a first step, the ecological and the information technological view of the product lifecycle are connected. Following, the AM process chain is integrated into the overall product lifecycle in the phases product development and manufacturing. Figure 2 shows the overall view of the product lifecycle connected with the AM process chain, called the holistic AM lifecycle.

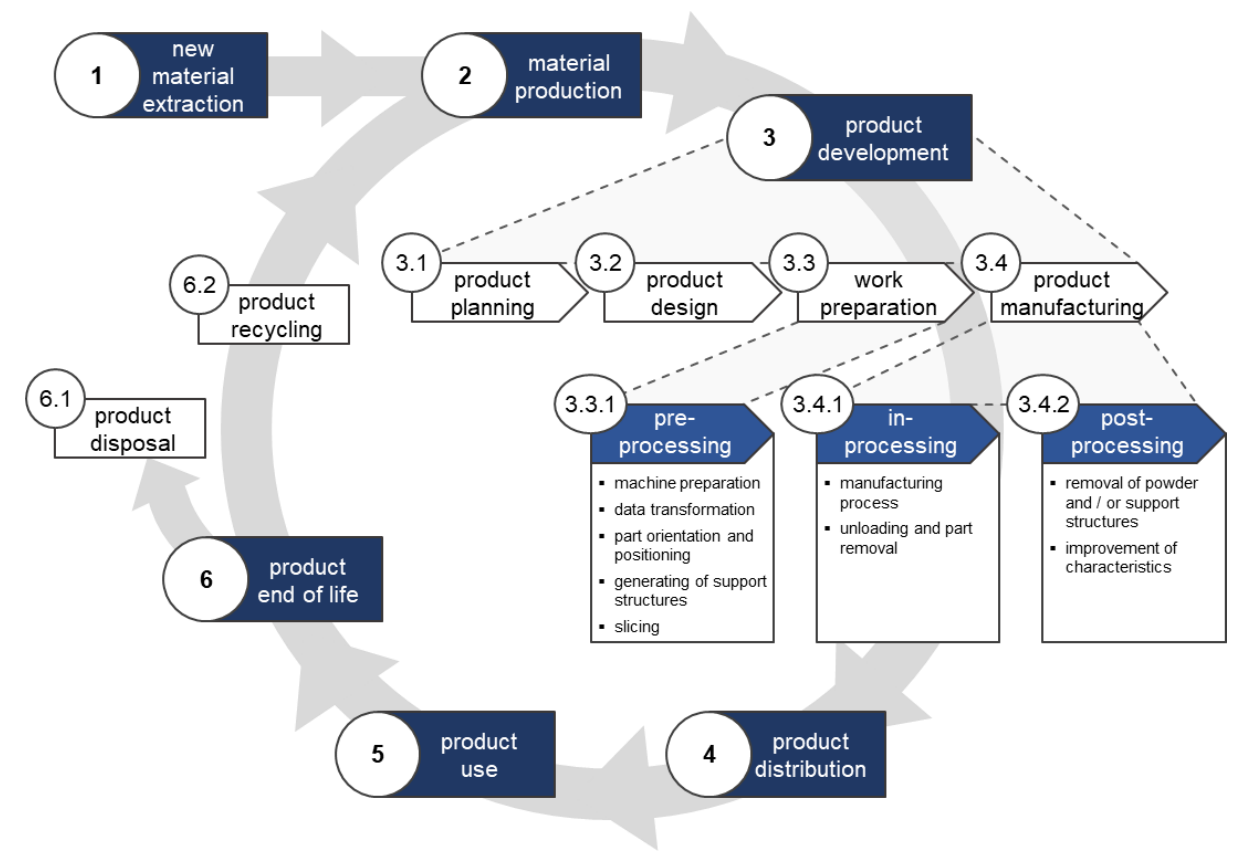

Fig. 2. The holistic AM lifecycle

The holistic AM lifecycle starts the first step of "new material extraction" (1). In this step, new raw material gets into the holistic AM lifecycle. In the beginning, this step is the starting point for the holistic AM lifecycle. The second step is the "material production" (2). In this step, the raw material is transformed into a usable form, for example powder or filament. The raw material and the usable form are depending on the selected AM method. The third step is the "product development" (3). This step can be divided in four minor steps, starting with the "product planning" (3.1). This step serves to establish the requirements for the desired product. The 3D CAD geometry of the 
desired component is developed in the step "product design" (3.2). The next step is the "work preparation" (3.3). In this step, the "pre-processing" (3.3.1) of the AM process chain is integrated. In this step, the machine is prepared, data is transformed, the part is oriented and positioned, support structures are generated and part and support structures are sliced in the end. The need of support structures depend on the chosen AM method. After the work preparation, the "product manufacturing" (3.4) follows. In this step, the "in-processing" (3.4.1) and the "post-processing" (3.4.2) are integrated. In the in-processing, the manufacturing process and the unloading and part removal take place. The post-processing serves for the removal of the powder or the support structures. Besides, the characteristics of the component can be improved in this step. An important improvement can be a surface treatment. After the step of product development, the "product distribution" (4) follows. In this step, the produced component becomes the property of the costumer. The fifth step is the "product use" (5). The component is still property of the costumer. Thus, the costumer decides on the time and way of usage. The sixth and last step is the "product end of life" (6). There are two possibilities for the product end of life, the "product recycling" (6.1) and the "product disposal" (6.2). Thus, the component is separated into individual parts. The parts can be recycled or disposed. If a component is produced with the fused deposition modeling for example, it can be shredded and the resulting material can be used again for material production. If materials are used, which cannot be recycled easily, they escape the lifecycle for disposal. It is possible that either both or only one step take effect for a component. Once the material flow is activated, the recycled material from step six might be sufficient to go through the holistic AM lifecycle again. In this case, the lifecycle starts with the second step "material production" after the recycling.

Figure 2 shows a sequential sequence. This describes the process chain to manufacture a component. The initial point is the material production or the new material extraction starting at the cradle. Some of the phases and the decisions made during one phase can affect other phases. For the holistic AM lifecycle, decisions for the design of the component and for the suitable AM manufacturing method need to be made. The decisions depend on the requirements for the product. The requirements of the product filter the manufacturing method. Besides, the requirements affect the choice of material, the product development in general and the product end of life.

The holistic AM lifecycle is an elementary step for a successful development of the concept for a holistic knowledge-based AM. To achieve a holistic knowledge-based $\mathrm{AM}$, data has to be collected in the different process steps. There exist four primary requirements for the concept and its implementation:

- Important process and lifecycle parameters need to be identified

- Data need to be collected for every important process parameter

- Collected data need to be analyzed and stored

- There has to be an additional benefit besides the storage of the data

The first requirement of the identification of important process parameters serves to create a benefit in the end. Only if the right parameters are identified, they can be collected, analyzed and optimized. Important process parameters have an impact on the 
quality of the part, process reliability, process time, process costs and process sustainability. The process parameters can concern the original AM process chain, the holistic AM lifecycle or the AM part itself. Besides the factors cost, quality, time and sustainability, they can contain information concerning the interaction of process steps.

The decision, which process parameters have an impact on the factors, is depending on the AM method and the depending process characteristics. In general, information about the following topics have to be collected concerning the holistic AM lifecycle:

\section{Choice of material:}

The AM method effects the choice of material. The material has an impact on the component behavior, besides the component design for example. Furthermore, the mechanical rigidity or material characteristics can change with material replacement. The choice of the material effects the material production, the product development and the product end of life with recycling or disposal of the component.

\section{Manufacturing information of the material:}

The material has an impact on the quality of the component. To achieve good quality, the material has to be faultless. Therefore, manufacturing information of the new material as particle size or filament diameter (depending on the manufacturing method) need to be collected. Process parameters as nozzle temperature help to monitor the process. Besides, environmental influences can have an impact and have to be documented. Significant environmental influences are humidity, ambient temperature and vibrations.

\section{Relation of new material to recycled material:}

To conserve high quality, the effect of recycled material on the behavior of the component has to be observed. For example, plastic powder changes the characteristics because of the heat through an AM process, even it is not sintered in the selective laser sintering process. Therefore, the relation of used or recycled material to new material is an important information.

\section{Information through product planning:}

Requirements concerning the behavior of the component have an impact on potential process parameters, for example layer sizes or manufacturing speeds. The planned usage of a part effects the design of the part and in the end, the manufacturing process. The requirements do not only address the product use, it can concern various phases of the lifecycle as the product development and the product recycling. Therefore, information of the product planning need to be conserved and connected.

\section{Product design:}

The design of the component results from the requirements on the product, the technical possibilities of the chosen manufacturing method and the characteristics of the material. The design effects the product characteristics, the reasonable orientation of the part and the economic efficiency. Moreover, the strived quality has an impact on the design. Potential improvements of the part characteristics have to be included in the design phase. Furthermore, desired functions of the component can be considered in the design phase and integrated directly. 


\section{Data transformation:}

Through the change of the data format mistakes can be occur. Common data format is the Standard Tessellation Language (STL). The transformation contains an approximation of the original geometry with the help of triangles. The approximation of the native CAD-geometry of the part has to take place in an appropriate way, as a trade of between data volume and approximation accuracy.

\section{Nesting, support and slicing:}

The nesting of the part has an impact on the quality of the whole part and the surface. With a false orientation of the part, the staircase effect can occur in the printing area and minor the quality of the part. Furthermore, the orientation has an impact on the mechanical resistance and residual stresses. With an unfavorably mechanical stress, delamination can be the result for example. Therefore, information about the nesting need be collected and included in quality control. Besides, the place and amount of support structures can have an impact on the part quality, the building time, surface qualities, process temperatures, and the costs. Therefore, information about the installing of support structures are collected. For the slicing, the layer thickness has to be decided as a trade of between building speed and component quality.

\section{Manufacturing information of the part:}

The collection of manufacturing information serves the process monitoring and the process optimization through analyses of the data. Important information are traverses, building speeds, temperatures of the nozzle or intensity of the laser, temperatures of the building space, vibrations and information about the used material. Abnormalities during the manufacturing process can affect the mechanical resistance of the component and the surface quality.

\section{Environmental influences during the manufacturing process:}

As for the material, the environmental influences during the manufacturing of the part can have an impact on the quality of the part and the manufacturing process. Important environmental influences are the temperature and the humidity. Furthermore, vibrations during the manufacturing process influence the accuracy of the building process and in the end, the quality of the component. The influences are documented to explain downstream effects as early failure of the part.

\section{Information of product distribution:}

Time and place are important, when the component changes from the property of the manufacturer to the user. The handling of the component during the distribution can have an impact on the quality and the function. With the product distribution, the warranty starts.

Time and way of the use of the manufactured part:

Time and way of the usage of the manufactured part can have an impact on the component lifetime. New findings about the effects may help to extend the lifetime. Information of this phase can help to develop a suitable component design depending on the usage and optimize the pre-processing with data transformation, part orientation and positioning. 


\section{Environmental influences during usage:}

Influences as for example temperature or humidity can have an impact on the component lifetime. The geographic place of usage has a significant impact. If the impact can be quantified, it can be factored in the component design.

\section{Recycling of disposal of the part:}

Based on the shortage of natural resources, recycling gets more important. Knowledge of recycling processes can affect future designs of components. Suitable designs for recycling are determined through the generation of a database. The requirements of the recycling process and the knowledge of suitable designs are integrated into the product design phase. Information concerning the material and the corresponding material behavior during and after a recycling process are relevant information for the material production phase. Besides an effect on the environment, a reasonable recycling concept reduces costs of material purchasing. To create a suitable recycling concept, information are needed.

\section{Return of information from phases into other phases:}

The kind and amount of information, which are fed back, can only be optimized, if these are documented. The benefit of returned information is controlled to optimize the data flows. The return of information is important for the efficient optimization of every phase of the AM lifecycle. Findings of the product use phase need to be included in the improvement process of the component design. Information of the recycling phase are important for the development of the component design and the material production.

An elementary approach is the data exchange through a database. Information are not only collected, they are analyzed to optimize the process stability. Furthermore, they are stored for long term analyses in case of an early component failure. Additionally, information are transferred to different phases of the overall AM lifecycle. The result of the implementation of a database is the creation of a holistic knowledge-based AM over the entire life cycle. With the help of the holistic approach, the overall AM lifecycle and the resulting products can be optimized comprehensively. To realize a holistic knowledge-based AM, a communication concept with a data management concept needs to be developed and implemented. To show the installation and the benefit of a holistic knowledge-based AM, the following chapter deals with an outlook on the implementation of the holistic approach.

\section{Outlook on the implementation of a holistic knowledge-based AM over the entire lifecycle}

The AM lifecycle phases have to be realized in the real or the virtual world. Therefore, the use case of a holistic knowledge-based fused deposition modeling (FDM) is chosen and described in the following. The main aim of the holistic knowledge-based AM is the collection and analyses of interesting process parameters. The parameters are collected through the installation of additional sensors in the whole AM lifecycle. An important task is the identification of components and their measured values. This is necessary to gain information concerning part quality and process reliability. 
In the phase "new material extraction", new material from outside the life cycle gets in. Therefore, new raw material is ordered and used in the second step, the "material production". For material production, a material extruder has been developed and build. Material in the form of granulate or shredded scrapped parts serve as raw material for the extruder. The material extruder produces new filament, which is collected on a spool and used in a following AM job. In the phase of the material production, data concerning the quality of the new filament are collected. With the help of sensors, the availability of new raw material is proved, the temperature of the extruder nozzle, the temperature of the water-cooling basin, the diameter of the new produced filament and the length of the produced filament are measured. The third phase of product development is realized through a working station for the product planning and design. Furthermore, a FDM printer represents the work preparation and the product manufacturing. To monitor the product manufacturing, a sensor to measure the temperature of the nozzle, a thermal imaging camera for the temperature distribution on the building platform and the manufactured layers, four piezo sensors to measure the vibrations of the whole machine, acceleration sensors to track the movement of the building platform and a sensor to track the amount of the used filament are installed. During the "product distribution", the component moves to the costumer for the following "product use" phase. For the "product end of life", the component is separated into individual parts and the decision of recycling or disposal is made. This decision depends on the used material. PLA used in the fused deposition modeling process can be shredded and used again in the second phase of material production. At the actual state, a shredder for components is developed to produce recycled raw material for the material production.

With the help of automated data analyses, the management system can inform if a measured parameter is outside the approvable range. This is a first step to develop and implement a quality control concept. To realize data collection, the implementation of the communication concept is necessary. In terms of Industrie 4.0, the communication is realized with the Message Queue Telemetry Transfer (MQTT) protocol. Therefore, all machines are enhanced to cyber physical systems. In case of the FDM lifecycle demonstrator, microcontroller are integrated into the machines to enable communication.

\section{$5 \quad$ Conclusion and outlook}

In the field of AM, data are rarely collected and analyzed for process optimization or quality improvement. To maximize the benefit of the data management, a holistic approach is necessary. Therefore, the original AM process chain is integrated into the ecological and the information technological view of the product lifecycle. This new holistic AM lifecycle starts at the new material extraction. The material production follows as second phase. The third phase is the product development. This contains the four smaller phases product planning, product design, work preparation and product manufacturing, where the pre-processing of the AM process is integrated into the work preparation and the in- and post-processing into the product manufacturing. The fourth phase is the product distribution. As fifth phase follows the product use. Finally, the product end of life is the sixth and last phase. This phase slits into the two possibilities 
of product recycling and product disposal. The realization of the phases is described shortly as an outlook on the implementation for the use case of fused deposition modeling. Next steps are the detailed explanation of the use case and the development of an installation plan for the sensors. The sensors have to be integrated into the holistic AM lifecycle. The communication between the sensors and a database as well as the storage of the data have to be examined. To collect sufficient data for process and quality optimization, the process needs to be automated.

\section{References}

1. Wohlers, Terry T. (2017): Wohlers Report - 3D Printing and Additive Manufacturing - State of the Industry - Annual Worldwide Progress Report; ISBN 978-0-9913332-3-3.

2. Wohlers, Terry (2018): Wohlers Talk - AM System Manufacturer Growth. http://wohlersassociates.com/blog/ from January 27, 2018.

3. Korner, Remziye (2017): Mit dem Titanbauteil aus dem 3D-Drucker befindet sich nun erstmals ein additiv gefertigtes Bauteil in der Serienproduktion einer Airbus 350 XWB Passagiermaschine. Online: https://www.3d-grenzenlos.de/magazin/3d-objekte/airbus-a350xwb-3d-gedrucktes-bauteil-27303023/

4. Krämer, Andreas (2017): Stratasys Direct Manufacturing druckt Teile des Airbus A350 XWB. Online: https://www.3d-grenzenlos.de/magazin/kurznachrichten/stratasys-directmanufacturing-airbus-a350-xwb-27288483/

5. Krämer, Andreas (2017): Automobilzulieferer Thomas Pazulla setzt auf 3D-Druck in der Serienproduktion. Online: https://www.3d-grenzenlos.de/magazin/kurznachrichten/thomaspazulla-3d-druck-fuer-serienproduktion-automobilteile-27261893/

6. Auth, C.; Arndt, A.; Anderl, R. (2017): Method for the evaluation of economic efficiency of additive and conventional manufacturing. In: 28th Solid Freeform Fabrication Symposium 2017, 07.08.-09.08.2017, Austin, Texas. Online. https://sffsymposium.engr.utexas.edu/sites/default/files/2017/Manuscripts/MethodfortheEvaluationofEconomicEfficiencyo.pdf

7. Promotorengruppe Kommunikation der Forschungsunion Wirtschaft - Wissenschaft (2013): Umsetzungsempfehlungen für das Zukunftsprojekt Industrie 4.0. Online: https://www.bmbf.de/files/Umsetzungsempfehlungen_Industrie4_0.pdf

8. Plattform Industrie 4.0 (2015): Umsetzungsstrategie Industrie 4.0 - Ergebnisbericht der Plattform Industrie 4.0. Online: https://www.bitkom.org/noindex/Publikationen/2015/Leitfaden/Umsetzungsstrategie-Industrie-40/150410-Umsetzungsstrategie-0.pdf

9. Verein Deutscher Ingenieure (2014): VDI 3405 - Additive Fertigungsverfahren - Grundlagen, Begriffe, Verfahrensbeschreibung.

10. Gibson, I.; Rose, D. W.; Stucker, B. (2010): Additive Manufacturing Technologies - Rapid Prototyping to Direct Digital Manufacturing. 1. Edition. Springer, New York Heidelberg Dordrecht London. doi: 10.1007/978-1-4939-2113-3

11. Grote, K.-H.; Engelmann, F.; Beitz, W.; Syrbe, M.; Beyerer, J.; Spur, G. (2014): Das Ingenieurwissen - Entwicklung, Konstruktion und Produktion. 1. Edition. Springer, Berlin Heidelberg. doi: 10.1007/978-3-662-44393-4

12. Anderl, R.; Trippner, D. (2000): STEP - Standard for the Exchange of Product Model Data. Eine Einführung in die Entwicklung, Implementierung und industrielle Nutzung der Normenreihe ISO 10303 (STEP). 1. Edition. Springer Fachmedien, Wiesbaden. doi: 10.1007/978-3-322-89096-2 